\title{
Restoration of Cerebellar Gray Matter Thickness by Methylcobalamin (6 Weeks Study)
}

\author{
AFTAB AHMED ${ }^{1}$, TAZEEN KOHARI ${ }^{2}$, QANBAR ABBAS NAQVI ${ }^{3}$, RANA MUHAMMAD ZEESHAN ${ }^{4}$, FAIZA IRSHAD $^{5}$, \\ ZAFAR IQBAL MALIK ${ }^{6}$ \\ ${ }_{1}^{1}$ Associate Professor of Anatomy, M. Islam Medical and Dental College, Gujranwala \\ ${ }^{2}$ Associate Professor of Anatomy, Islam Medical and Dental College, Pasrur Road, Sialkot \\ ${ }^{3}$ Senior Demonstrator Anatomy, Islam Medical and Dental College, Pasrur Road, Sialkot \\ ${ }^{4}$ Senior Demonstrator Anatomy, Islam Medical and Dental College, Pasrur Road, Sialkot \\ ${ }^{5}$ Associate Professor of Anatomy, M. Islam Medical and Dental College, Gujranwala \\ ${ }^{6}$ Assistant Professor Anatomy, Sahara Medical College, Narowal. \\ Correspondence to Dr. Tazeen Kohari, Email: tazeenk67@gmail.com.Phone: 0323-2967849
}

\begin{abstract}
Background: Methylcobalamin is essential vitamin required for DNA synthesis during cell division therefore maintain the architecture of nervous tissue distorted by soft metals such as Lithium Carbonate. Accurate documentation of the thickness cerebellar cortical thickness was required in subjects who were injected with methylcobalamin distorted by Lithium Carbonate.

Aim: To provide data of cerebellar gray matter thickness distorted by Lithium Carbonate by the anti-oxidant effect of methylcobalamin.

Methods: Fifteen albino rats were maintained on food and diet in Animal House of the Basic Medical Sciences Institute, JPMC Karachi for a period of 6 weeks.

Results: The results obtained of the thickness of cerebellar gray matter distorted by Lithium Carbonate was restored by methylcobalamin in our study.

Conclusion: To observe the neuroprotective effect of B12 on distorted cerebellar cortex treated by Lithium Carbonate.

Keywords: Methylcobalamin, Lithium Carbonate, Gray Matter, Cerebellum
\end{abstract}

\section{INTRODUCTION}

The cerebellum is the largest sensorimotor structure ${ }^{1}$, it comprises of a thin layer of gray matter which covers the white matter. Gray matter contains climbing and mossy fibres, five types of neurons (basket, stellate, Golgi, purkinje, granule) and three layers molecular, purkinje and granular cell layer. ${ }^{2}$

Lithium an alkali metal discovered in 1817 was used in $19^{\text {th }}$ century for bipolar disorder and depression. ${ }^{3,4} \mathrm{~A}$ permanent cerebellar syndrome was reported by the use of Lithium $^{5}$ and methylcobalamin promoted the normal histology and thickness of gray matter 6 .

B12 is essential for cell growth and maintenance of normal myelin in nervous system ${ }^{7}$. Methylcobalamin deficiency leads to irreversible cerebellum damage ${ }^{8}$ and chronic treatment with it leads to scavenging of reactive oxidant species, which results in restoration of nervous $s$ tissue $^{9}$

\section{METHODOLOGY}

The present experimental study was conducted in the Department of Anatomy, BMSI, and JPMC Karachi. Fifteen animals weighing 180-200 grams were selected and kept under observation for one week prior to experiment for this study. Group C animals were given Lithium Carbonate 20 $\mu \mathrm{g} / \mathrm{kg}$ body weight $O D^{10}$ and injection methyl cobalamin at a dose of $200 \mu \mathrm{g} / \mathrm{kg}$ body weight ip/OD ${ }^{11}$ for a period of 6 weeks.

Received on 12-01-2021

Accepted on 24-05-2021
Sacrifice: Animals were sacrificed at the end of 6 weeks after removing the brain from the skull. Cerebellar tissue was taken and processed. Paraffin blocks ${ }^{12}$ were prepared and stained with haematoxylin and eosin.

Thickness of gray matter was measured with ocular micrometer and thickness was taken from the surface of cerebellar folia to the base of the gray matter. Statistical Analysis was performed using SPSS version 20 .

Statistical analysis: Statistical analysis was conducted by using software SPSS (statistical program for social sciences) 2007 version-16. Statistical differences between means and experimental data were carried out by student ' $t$ ' test. The difference was regarded highly significant if the $p$-value was equal or less than 0.001 , significant, when $p$ value is 0.005 to 0.049 , significant when $p$-value is 005 for this study.

\section{RESULTS}

Mean Values of the Thickness of Gray Matter $(\mu \mathrm{m})$ of Cerebellum in Group-C animals. In our study. The thickness of the cerebellar gray matter was found to be highly significantly restored in group $\mathrm{C}$ animals as the antioxidant methylcobalamin was also given along with the lethal drug which was Lithium carbonate

\begin{tabular}{|l|l|l|l|}
\hline \multirow{2}{*}{ Group } & \multicolumn{3}{|c|}{$\mathbf{6}^{\text {th }}$ Week } \\
\cline { 2 - 4 } & Mean & SEM & P value \\
\hline C & 281.6 & 2.59 & $<0.001^{* * * *}$ \\
\hline \multicolumn{2}{|c|}{ Normal Diet + Lithium + Injection Methylcobalamin } \\
\hline
\end{tabular}

${ }_{* \star \star *}$ Highly Significant 


\section{DISCUSSION}

The present study was designed to evaluate and document the protective role of $\mathrm{B} 12$ in Lithium Carbonate induced cerebellar gray matter toxicity in albino rats. This study was carried out by observing and recording the change in gray matter distorted by Lithium Carbonate and restored by vitamin B12.

Gomez and Lucas ${ }^{12,13}$ in their study observed that Lithium administration causes glycogen synthetase kinase inhibition which initiates apoptosis and causes neuronal cellular degradation.

The levels of Lithium induced apoptosis were highest in the rat cerebellum given that, mammalian central nervous system has limited regenerative capacity, it is of utmost importance, to limit the damage through therapeutic strategies $^{15}$ and methylcobalamin inhibits neuronal apoptosis also acted as an antioxidant agent ${ }^{16}$ in our study. The same neuroprotective effect on methylcobalamin was observed by Calderon-Ospin et $\mathrm{al}^{16}$. They in their study reported that exposure to vitamin B12 protects cerebellar gray matter degenerated by Lithium toxicity. The same effect of B12 is reported in our study which showed a marked decrease in thickness of gray matter of cerebellar cortex in Lithium treated group but restored by methylcobalamin ${ }^{17}$.

\section{CONCLUSION}

In the light of above consideration Lithium Carbonate proved to be neurotoxic at a dose of $20 \mathrm{mg} / \mathrm{kg}$ in albino rats and the damage was reversed by methylcobalamin. This study proves that methylcobalamin should be used in human population suffering from cerebellar toxicity.

\section{Conflict of interest: Nil}

\section{REFERENCES}

1. Lawrenson C, Bares M, Kamondi A, Kovacs A, Lumb B, Apps $R$, Philip P, Manto M. The Mystery of the cerebellum clues from experimental and clinical observations .Cerebellar Ataxias 2018; 5:8

2. Fitzgerald. Cerebellum. In: Standring S, Ellis H, Healy JC, Johnson D. Williams A, editors, Gray's Anatomy. $42^{\mathrm{N}}$ edition. Edinburgh: Elsevier Churchill Livingstone, 2017, p 353-68.

3. Mohandas E, Rajmohan V. Lithium use in special populations. Indian J Psychiatry. 2007; 49(3): 211-218.

4. Disorder. Tondo. Vázquez GH, Baldessarini J. Curr Neuropharmacology. 2017 Apr; 15(3):353-358. doi: $10.2174 / 1570159 \times 14666160606210811$
5. Sarrigiannis, P.G., Zis, P., Unwin, Z.C. et al. Tremor after long term lithium treatment; is it cortical myoclonus?. Cerebellum ataxias 6, 5 (2019). https://doi.org/10.1186/s40673-019-0100y

6. Wu F, Xu K, Liu L, Zhang K, Xia L, Zhang M, Teng C, Tong $\mathrm{H}$, He $\mathrm{Y}$, Xue $\mathrm{Y}$, Zhang $\mathrm{H}$, Chen $\mathrm{D}$, Hu A. Vitamin $B_{12}$ Enhances Nerve Repair and Improves Functional Recovery After Traumatic Brain Injury by Inhibiting ER StressInduced Neuron Injury. Front Pharmacol. 2019 Apr 24;10:406. doi.

7. Calderón-Ospina CA, Nava-Mesa MO.CNS Neurosci Ther. 2020 Jan;26(1):5-13. doi: 10.1111/cns.13207. Epub 2019 Sep 6

8. van d Lagemaat EE, de Groot Lisette CPGM, van den Heuvel Ellen GHM. Vitamin B12 in Relation to Oxidative Stress: A Systematic Review. Nutr Feb 2019, 11(2): 482. Published online, doi 10.3390/nu11020482

9. Chmielnicka $\mathrm{J}$ and Nasiadek $\mathrm{M}$.The. trace elements in response to Lithium intoxication in renal failure. Ecotoxicol Environ Saf 2003: 55 (2 178-83.)

10. Tamaddonfard E, Samadi F, Egdami K. The effects of vitamin B12 and their combination on cold and mechanical allodynia in a neuropathic pain model in rats. Research Forum. 2013; 4 (1) $19-24$.

11. Shaikh BA. The radioprotective role of methycobal on cerebellar cortex of young albino rats: A histological study. M.Phil Thesis, Department of Anatomy, BMSI, JPMC, Karachi, 2010; 39

12. Gomez-Sintes R, Lucas JJ.NFAT/Fas signaling mediates the neuronal apoptosis motor side effects of GSK-3 inhibition in a mouse model of lithium therapy .; 120(7):2432-45. doi: 10.1172/JCl37873. Epub 2010 Jun 7.

13. Snitow ME, Bhansali RS, Klein PS. Lithium and Therapeutic Targeting of GSK-3. Cells. 2021 Jan 28;10(2):255. doi: 10.3390/cells 10020255 .

14. Friediander RM. Apoptosis and caspases in neurodegenerative diseases. Engl J Med, 2003; 348:1365-75.

15. Vitamin B12 deficiency results in severe oxidative stress, leading to memory retention impairment in Caenorhabditis elegans, Tomohiro Bito, Taihei Misaki, Yukinori Yabuta, Takahiro Ishikawa, Tsuyoshi Kawano Fumio Watanabe,Redox Biology,Volume 11,2017, Pages 21-29,

16. Calderon-Ospina CA, Nava-Mesa MO. B vitamins in the nervous system: Current knowledge of the biochemical modes of action and synergies of thiamine, pyridoxine and cobalamin. 6 Sep 2019, https://doi.org/10.1111/cns.13207

17. Tathagat $M$, Nadeem A, Mishra S, Chaudhary M, Joshi DK, Advani U, Tripathi S. Antioxidant status in Lithium induced cerebellar toxicity in rat CNS, Dissertation. NIM University Shobha Nagar India; 2012; p1-15. 